\title{
VOLATILE COMPOUNDS IN CACHAÇAS OBTAINED FROM THREE SUGARCANE VARIETIES CULTIVATED UNDER THE MANAGEMENTS: ORGANIC, CONVENTIONAL AND WITHOUT FERTILIZATION
}

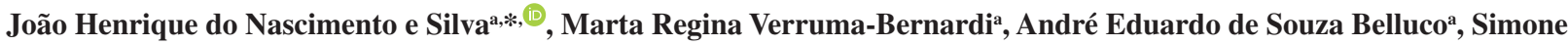 \\ Daniela Sartorio de Medeiros $^{\mathrm{b}}$ and Alessandra Lopes de Oliveira ${ }^{\mathrm{c}}$ \\ ${ }^{a}$ Departamento de Tecnologia Agroindustrial e Socioeconômica Rural, Universidade Federal de São Carlos, 13600-970 Araras - \\ SP, Brasil \\ bDepartamento de Informática e Estatística, Universidade Federal de Santa Catarina, 88040-370 Florianópolis - SC, Brasil \\ 'Departamento de Engenharia de Alimentos, Universidade de São Paulo, 13635-900 - Pirassununga - SP, Brasil
}

Recebido em 06/04/2020; aceito em 22/06/2020; publicado na web em 07/08/2020

\begin{abstract}
The volatile compounds present in cachaça can derive from the raw material used in the production of the beverage, from the fermentative process, from distillation or aging. The aim of the research was to evaluate the volatile compounds, in the cachaças from stills produced with different sugarcane varieties, under the organic and conventional managements. The varieties RB867515, RB962869 and RB85553 were cultivated in three distinct ways, planting without fertilization (OUTF); organic planting (ORGN) and conventional planting (CONV). The results showed that for the total esters, higher alcohols and coefficient of congeners present in the cachaça, the varieties and managements are dependent, unlike volatile acidity, total aldehydes, methyl alcohol and furfural. Therefore, the quality, origin and lineage of the sugarcane variety used for the production of cachaça were confirmed to influence the chemical concentrations of the volatile compounds of the beverage, modifying its chemical profile. It is worth reinforcing that none of the volatiles presented concentration above that allowed by the Brazilian legislation.
\end{abstract}

Keywords: volatile compounds; sugarcane; managements; varieties; total acidity.

\section{INTRODUCTION}

Alcoholic beverages known as yeast-distillates are made up of hundreds of volatile compounds in different concentrations. These volatile compounds are also known as secondary components; they are responsible for composing the peculiar "bouquet" of each beverage. Secondary compounds are formed at the same time with ethyl alcohol during the wort fermentation process, the concentrations can vary throughout the distillation. ${ }^{1}$ The sum of the volatile compounds found in cachaça, the limit of which is established by the Normative Instruction 13 of MAPA, also known as secondary components of the beverage, must be between 200 and $650 \mathrm{mg}$ per $100 \mathrm{~mL}$ of anhydrous alcohol. ${ }^{2}$

Acetaldehyde is the major aldehyde present in cachaças corresponding to about $90 \%$ of the total aldehydes in beverages. The concentration of this compound is reported as the actual level of aldehyde in the beverage. Esters in the cachaça can, however, be derived from reactions of esterification between an acid and an alcohol, for example. This reaction can be catalyzed by enzymes (esterase) or chemically occurring without the enzymatic contribution. The higher alcohols are found in cachaças and are classified as the main representatives of the group secondary compounds. ${ }^{3}$

Furfural is an organic aromatic heterocyclic compound, classified as aldehyde, found at low levels in cachaças, resulting from the chemical decomposition of carbohydrates, being the presence of methanol in cachaça undesirable, due to its toxicity to the consumer. ${ }^{4}$

Excessive volatile acidity can promote an undesirable and slightly aggressive taste to the consumer's taste, depreciating the quality. Acetic acid is found in cachaça. The formation of n-butanol in alcoholic beverages is related to yeast strain, nutrients in the medium, temperature, $\mathrm{pH}$ and the presence of nitrogen compounds. ${ }^{5}$

*e-mail: joao_henrique@ hotmail.com
Sugarcane is the raw material for the production of cachaça in Brazil, it is widely cultivated in the conventional cultivation system, with the practice of monoculture, with the production or agricultural culture of only a single type of agricultural product. This system has been the target of criticism regarding the negative socio-environmental impact and human health. Due to the risks, researchers are looking for alternative systems for the production of sugarcane, for example, organic agriculture, which provides economic interaction with the search and creation of more balanced ecosystems, the preservation of biodiversity and biological activities from soil. ${ }^{6}$ Therefore, the objective of the present research was to evaluate the volatile compounds, in the cachaças of stills produced with different varieties of sugarcane, under the organic and conventional management.

\section{MATERIAL AND METHODS}

\section{Experimental planning}

The minority volatile compounds were analyzed in the cachaças derived from sugarcane of the varieties RB857515, RB966928 and RB855453, planted without fertilization and with organic and conventional fertilization. Each plot had $37 \mathrm{~m}^{2}$, with 5 furrows of 5.0 $\mathrm{m}$ in length and spacing of $1.5 \mathrm{~m}$ between the lines, where the three central furrows formed the useful area of the plot and two lateral furrows as borders.

\section{Determination of the volatile compounds}

In Brazil, the determination of the minor volatile compounds in cachaça is regulated by the Ministry of Agriculture, Livestock and Supply and uses the Gas Chromatography and Flame Ionization Detector (GC/FID). In this research, the analyses were performed in a Gas Chromatograph (GC) (Shimadzu, model QP-2010 PLUS, Kyoto, JP), with a Nukol ${ }^{\mathrm{TM}}$ column (polyethylene glycol, 
$30 \mathrm{~m} \times 0.25 \mathrm{~mm} \times 0.25 \mu \mathrm{m}$ ) and a flame ionization detector (FID). The temperatures of the detector and injector were fixed at $190{ }^{\circ} \mathrm{C}$ and the manual mode of injection with flow division (split) of 1:15 with an injection volume of $1.0 \mu \mathrm{L}$ of sample, in triplicate. The flow of the drag gas in the column $\left(\mathrm{H}_{2}\right)$ was of $3.38 \mathrm{~mL} \mathrm{~min}^{-1}$ with total flow of $57 \mathrm{~mL} \mathrm{~min}^{-1}$ and pressure of $115 \mathrm{KPa}$. The programming of the column temperature ramp was of $40^{\circ} \mathrm{C}$ (isotherm of $4 \mathrm{~min}$ ), rise until $150{ }^{\circ} \mathrm{C}$ at a rate of $32^{\circ} \mathrm{C} \mathrm{min}^{-1}$ (isotherm of $5 \mathrm{~min}$ ) and increase

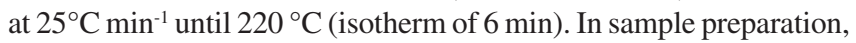
the cachaças were filtered in filter paper with grammage of $80 \mathrm{~g} \mathrm{~m}^{-2}$ and porosity of $3 \mu \mathrm{m}$ (Nalgon, São Paulo, BR). Subsequently, these samples were manually injected into the GC. ${ }^{7}$

The quantification of the volatile compounds was performed by external standardization; for this, a standard solution with known concentrations of acetaldehyde, ethyl acetate, ethanol, acetal, methanol, isopropanol, sec-butanol alcohol, n-propanol, n-Butanol, iso-butanol alcohol, iso-amyl alcohol, n-amyl alcohol and furfural was prepared in different concentrations. The linear regression of the points which correlate the different concentrations of the compounds at the different dilutions of the standard mixture with the areas of the corresponding chromatographic peaks generated the equation used in the calculation of the concentration these volatiles (Table 1). The reagents employed were of analytical grade, without the need for purification.

\section{Determination of the alcohol content}

The alcoholic degree of cachaça was carried out by the densimetric method. $200 \mathrm{ml}$ of the drink was measured in a volumetric flask. The temperature of the liquid was recorded and maintained at a temperature of $20^{\circ} \mathrm{C}$. The sample was transferred to the round bottom flask of the distillation apparatus and the volumetric flask was washed with 3 (three) volumes of approximately $20 \mathrm{~mL}$ of distilled water. The washing waters were added to the contents of the distillation flask. Glass beads were introduced into the distillation flask.

Then $20 \mathrm{~mL}$ of distilled water was added to the initial $200 \mathrm{~mL}$ volumetric flask, which was used to collect the distillate. The flask was placed in a cold water bath $\left(10\right.$ to $\left.15^{\circ} \mathrm{C}\right)$. The distillation was carried out, avoiding the phenomena of entrainment and carbonization, stirring the contents of the flask from time to time, until the distillate level was a few millimeters below the volumetric flask gauge. When the temperature of the collected distillate was below the initial liquid temperature $\pm 0.5^{\circ} \mathrm{C}$, finally, the volume was made up with distilled water to the gauge and homogenized. This distillate was used to determine the actual alcoholic strength. When necessary, the alcoholic strength of the drink was measured with ultra-purified distilled water. All cachaças were standardized to $49 \% \mathrm{v} / \mathrm{v}{ }^{7}$

\section{Determination of the total acidity}

The total acidity has the limit established by the Normative Instruction $n^{\circ} 13$ of the Ministry of Agriculture, Livestock and Supply - MAPA. ${ }^{2}$ The determination of the volatile acidity in cachaça is based on the titration of the volatile acids extracted from the sample by drag of water vapor by the titrimetric principle. In this analysis, $10 \mathrm{~mL}$ of the sample was stored in a round-bottomed flask with additional $250 \mathrm{~mL}$ of distilled water and coupled to the rotary evaporator to evaporate. The thermostatic bath of the rotary evaporator was regulated at the temperature of $85^{\circ} \mathrm{C}$ for volatilization and the drag of the volatile acids present in the sample to occur. ${ }^{2}$

The condenser and the whole enclosed assembly were connected to a vacuum system. The condenser coil condensed the acid vapors that were collected in the distiller collection flask until the volume of $100 \mathrm{~mL}$. This volume of the distillate was transferred to a 250 mL-Erlenmeyer and 03 drops of the indicator phenolphthalein were added. The titration of the volatile acidity of the distillate was then performed using a manual graduated burette of $50 \mathrm{~mL}$ with $0.1 \mathrm{~N}$ sodium hydroxide until the turning point. The volatile acidity was expressed in grams of acetic acid per $100 \mathrm{~mL}$ of sample $\left(\mathrm{g} 100 \mathrm{~mL}^{-1}\right)$. The volatile acidity $(A v)$ was calculated by equation $1 .^{2}$

$$
\mathrm{Av}=\frac{E q \cdot n \cdot N}{10 . \mathrm{V}}
$$

where: $A v$ is the titrable volatile acidity; $n$ is the volume of the sodium hydroxide solution spent in titration, in $\mathrm{mL} ; N$ is the Normality of the sodium hydroxide solution; $V$ is the sample Volume, in $\mathrm{mL} ; E q$ is the gram-Equivalent of the acetic acid $\left(60 \mathrm{~g} \cdot \mathrm{mol}^{-1}\right)$, since the unit of the analysis is expressed in gram of acetic acid.

\section{Statistical analysis}

The experimental design employed was completely randomized $(\mathrm{CRD})$ in factorial scheme 3 (varieties) $\times 3$ (managements) and was performed in 4 repetitions.

The results of the concentration of these volatile compounds present in the cachaça were evaluated and subjected to the analysis of variance $(\mathrm{p} \leq 0.05)$ and the Tukey's multiple comparisons test. The software $R$ Development Core Team ${ }^{\circledR}$ was used. ${ }^{8}$

\section{RESULTS AND DISCUSSION}

\section{Volatile compounds}

In Figure 1, the peaks of the standard mixture and presented, as well as the same peaks in the cachaça prepared with variety RB855453 under the management without fertilization, in the Figure 2. Although with different intensities, the volatile compounds are present in the beverage; nevertheless, there are other volatile compounds in the beverage in lower intensities.

\section{Total aldehydes}

The concentration of total aldehydes expressed in acetaldehyde concentration was determined by equation (2) (Table 1). The concentration of total aldehydes ( $\mathrm{mg}$ of acetaldehyde per 100 $\mathrm{mL}$ of anhydrous alcohol) in the cachaças was evaluated and subjected to the univariate analysis of variance, at the level of 5\% of significance and the Tukey's test. The double interaction was not significant $(p$-value $=0.051379)$, indicating that the variety was not dependent on the management in relation to the concentration of this volatile. When the Tukey's means were evaluated for the analysis of simple effect, a significant difference was found among the varieties $(\mathrm{p}$-value $=0.000002)$ and among the managements $(\mathrm{p}$-value $=0.000001)($ Table 2$)$.

The mean concentration of total aldehydes in the cachaças (Table 2) was of $24.3 \mathrm{mg} .100 \mathrm{~mL}^{-1}$ of anhydrous alcohol. The values all samples are in agreement with the Brazilian legislation which determines the maximum content of total aldehydes, expressed in acetaldehyde of $30 \mathrm{mg} \mathrm{L}^{-1}$ of anhydrous alcohol.

The concentration of aldehydes in the cachaças produced with different species varied from 20.24 to $28.21 \mathrm{mg}$ of acetaldehyde per $100 \mathrm{~mL}$ of anhydrous alcohol. All acetaldehyde concentrations in the cachaças derived from the three varieties differed from each other.

The variety RB867515 presented the highest concentration for the levels of total aldehydes, an important information to the sector, 


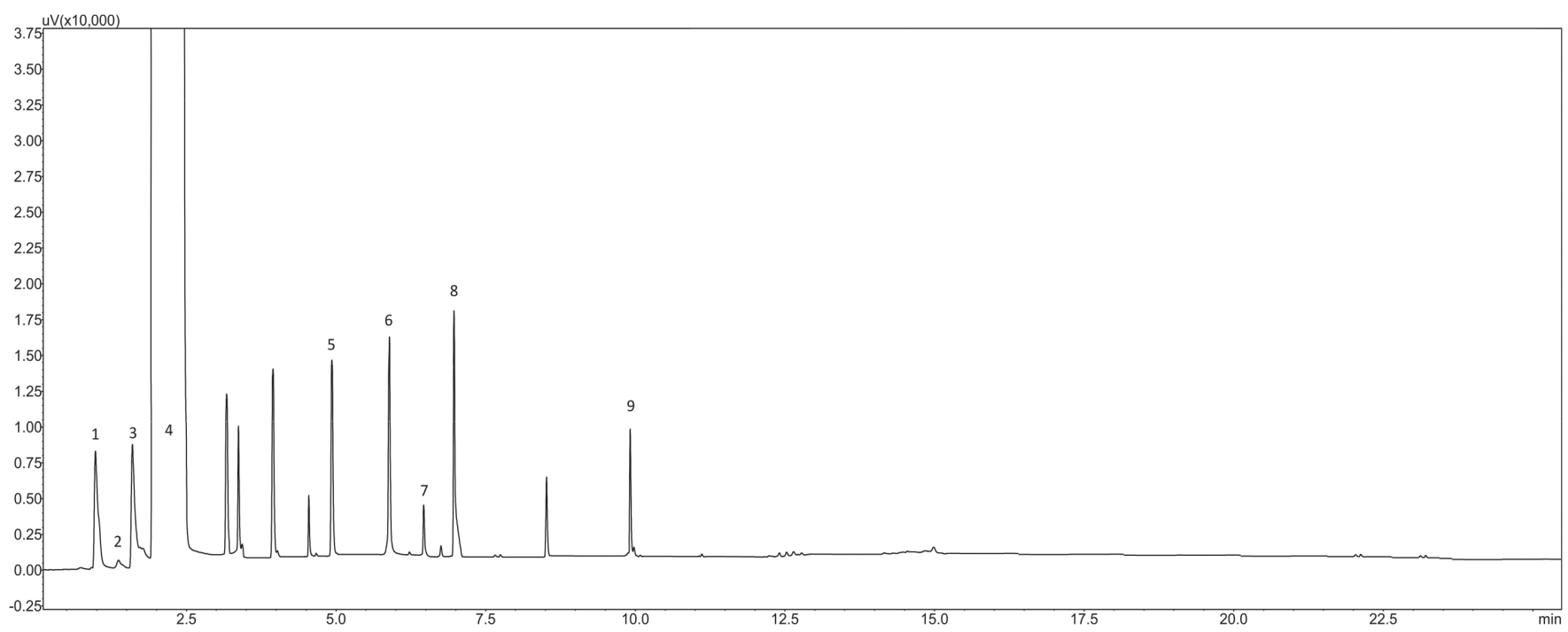

Figure 1. Chromatogram of the standard volatile mixture. - 1 - acetaldehyde; 2 - methanol; 3 - ethyl acetate; 4 - ethanol; 5-n-propanol; 6 - n-butanol; 7 - isobutanol; 8 -isoamylic; 09 - furfural

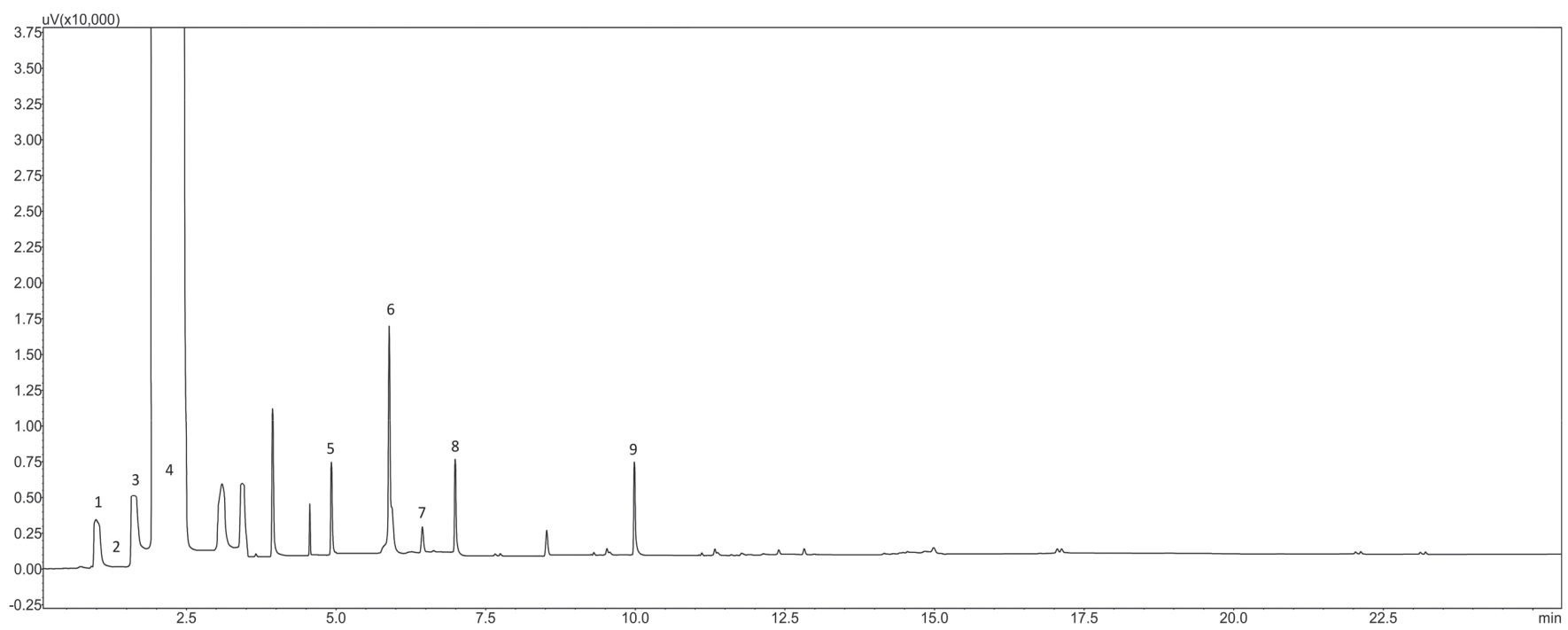

Figure 2. Chromatogram of the cachaça (RB855453 - Without fertilization) - 1 -acetaldehyde; 2 - methanol; 3 - ethyl acetate; 4-ethanol; 5- n-propanol; 6-n-butanol; 7 - isobutanol; 8-isoamylic; 09 - furfural

Table 1. Equations derived from the linear regression which correlates the known concentration of each volatile in the standard mixture with the area of the chromatographic peak

\begin{tabular}{lccc}
\hline Volatile & $\begin{array}{c}\text { Concentration } \\
(\mathrm{mg} \mathrm{100} \mathrm{mL}-1)\end{array}$ & Equation & Eq. \\
\hline $\begin{array}{l}\text { Total aldehydes } \\
\text { (acetaldehyde) }\end{array}$ & $6-42$ & $\mathrm{y}=44.183 \mathrm{x}-1.2821$ & {$[2]$} \\
$\begin{array}{l}\text { Esters (ethyl } \\
\text { acetate) }\end{array}$ & $12-66$ & $\mathrm{y}=158.780 \mathrm{x}-1.057,6$ & {$[3]$} \\
N-propanol & $8-48$ & $\mathrm{y}=748.281 \mathrm{x}-218.891$ & {$[4]$} \\
Isobutanol & $20-120$ & $\mathrm{y}=762.665 \mathrm{x}-460.989$ & {$[5]$} \\
Isoamylic & $2-120$ & $\mathrm{y}=7.825,4 \mathrm{x}-392,17$ & {$[6]$} \\
Furfural & $0.5-3.0$ & $\mathrm{y}=1.359,8 \mathrm{x}-386,59$ & {$[7]$} \\
Methanol & $2-12$ & $\mathrm{y}=54.127 \mathrm{x}-25.043$ & {$[8]$} \\
N-Butanol & $0.3-1.8$ & $\mathrm{y}=40.543 \mathrm{x}+426.469$ & {$[9]$} \\
\hline
\end{tabular}

since it was the most cultivated RB variety (65\%) in the harvest of 2015 in Brazil. ${ }^{9}$ Analyzing total aldehydes in beverages produced from different sugarcane varieties, did not find a significant difference among the beverages for this variable..$^{10}$
Table 2. Tukey's means of the concentration of total aldehydes of the analysis of simple effect for the varieties and for the managements

\begin{tabular}{lc}
\hline Varieties & Means \\
\cline { 2 - 2 } & mg per $100 \mathrm{~mL}$ of anhydrous alcohol \\
\hline RB867515 & $28.21^{\mathrm{a}}( \pm 6.02)$ \\
RB855443 & $24.45^{\mathrm{b}}( \pm 3.91)$ \\
RB966928 & $20.24^{\mathrm{c}}( \pm 3.97)$ \\
Managements & Means \\
Organic & $28.48^{\mathrm{a}}( \pm 5.09)$ \\
Without fertilization & $20.45^{\mathrm{b}}( \pm 3.57)$ \\
Conventional & $24.24^{\mathrm{a}}( \pm 4.09)$ \\
\hline
\end{tabular}

Equal letters indicate that, at the level of $(\mathrm{p} \leq 0.05)$ of significance, there is no difference among the means.

The mean concentration of total aldehydes from the management without fertilization $(20.45 \mathrm{mg}$ of acetaldehyde per $100 \mathrm{~mL}$ of anhydrous alcohol) was different from the organic management (28.48 $\mathrm{mg}$ of acetaldehyde per $100 \mathrm{~mL}$ of anhydrous alcohol), 
but the organic management did not differ from the conventional management $(24.24 \mathrm{mg}$ of acetaldehyde per $100 \mathrm{~mL}$ of anhydrous alcohol) (Table 2).

Although no significant differences were detected between the acetaldehyde concentrations in the cachaças derived from the fertilizations (organic or mineral), differences were detected between them and the one without fertilization. Considering that the process was the same for all assays, it is verified that fertilization, somehow, has contributed for the beverages to reach higher contents of total aldehydes.

\section{Esters}

The concentration of esters in the cachaças produced with different management conditions and varieties is expressed in ethyl acetate. To calculate the concentration, equation (2) was employed (Table 1) considering the area of the peaks of this compound in the cachaças.

The concentrations of total esters (mg of ethyl acetate per $100 \mathrm{~mL}$ of anhydrous alcohol) in the different cachaças indicated that the double interaction was significant $(p$-value $=0.00059885)$ and that the variety was dependent on the management regarding the concentration of total esters in the beverage (Table 3).

Table 3. Means of the concentration of esters in the cachaças in the unfolding of the double interaction (varieties $\times$ managements)

\begin{tabular}{|c|c|c|c|}
\hline \multirow{3}{*}{ Management } & \multicolumn{3}{|c|}{ Variety } \\
\hline & RB867515 & RB855453 & RB966928 \\
\hline & \multicolumn{3}{|c|}{$\mathrm{mg}$ per $100 \mathrm{~mL}$ of anhydrous alcohol } \\
\hline Organic & $34.12^{\mathrm{Aa}}$ & $24.93^{\text {Ba }}$ & $26.63^{\mathrm{Ba}}$ \\
\hline Conventional & $38.27^{\mathrm{Aa}}$ & $22.50^{\mathrm{Ba}}$ & $24.32^{\mathrm{Ba}}$ \\
\hline Without fertilization & $28.73^{\mathrm{Ab}}$ & $16.43^{\mathrm{Bb}}$ & $13.89^{\mathrm{Bb}}$ \\
\hline
\end{tabular}

Values in the same line, followed by identical capital letters, or in the same column followed by identical lowercase letters indicate that, at the level of significance $(\mathrm{p} \leq 0.05)$, there is no difference among the means.

In the analysis of the means for the levels of total esters in the cachaças, among all managements, the sugarcane variety RB867515 differed significantly from varieties RB855453 and RB966928 (capital letters in the same line) (Table 3). This result evidences that the sugarcane variety, because of its specific features, causes differences in the levels of total esters in the cachaça.

For the levels of total esters, it is emphasized that there was a significant difference in the cachaça produced from sugarcanes without fertilization in the planting (lowercase letters in the same column) (Table 3). Nevertheless, fertilization (organic or mineral) has influenced the sugarcane varieties for a higher formation and levels of total esters in the beverage. No studies have been found evaluating total esters between beverages from conventional and organic managements.

Esters contribute to the characterization of cachaça, in physicalchemical and sensory terms. After analyzing the results of the total esters concentrations (Table 3), but close to the values found by Lima et al. ${ }^{11}$

In addition to the irregular collection of the beverage fraction, high levels of total esters in the cachaças can also be attributed to factors such as the addition of a nitrogen supplement in the fermentation, use of micronutrients, level of establishment of the fatty acids present in the fermentation, yeast strains, sudden oscillations in fermentation temperature and the quality of the sugarcane which has originated the must. The sugarcanes and beverage production were maintained under rigorous procedure to avoid differentiations in the process. ${ }^{12}$

\section{Higher alcohols}

According to the legislation, the levels of higher alcohols in cachaça come from the sum of the n-propanol, isobutanol and isoamyl alcohols. The maximum limit is of $360 \mathrm{mg}$, expressed by the sum of these alcohols, in $100 \mathrm{~mL}$ of anhydrous alcohol. ${ }^{2}$ The concentration of higher alcohols was determined in relation to the chromatographic peaks of the higher alcohols in the cachaça determined by equation (4) for n-propanol, equation (5) for isobutanol alcohol and equation (6) for isoamyl alcohol (Table 1).

The concentrations of higher alcohols in the cachaças were evaluated and the double interaction was significant ( $p$-value $=0.00059885)$, indicating that the variety is dependent on the management in relation to the concentration of these compounds (Table 4).

In all management systems, the Tukey's means of the sugarcane varieties differed significantly from each other (Table 4). The varieties influenced the levels of higher alcohols in the beverage, for how much that the levels of higher alcohols in cachaça might suffer an influence from the composition and origin of the raw material and must used for beverage production. ${ }^{1}$

Table 4. Means of the concentration of higher alcohols in the cachaças in the unfolding of the double interaction (varieties $\times$ managements)

\begin{tabular}{|c|c|c|c|}
\hline \multirow{3}{*}{ Management } & \multicolumn{3}{|c|}{ Variety } \\
\hline & RB867515 & RB855453 & RB966928 \\
\hline & \multicolumn{3}{|c|}{$\mathrm{mg}$ per $100 \mathrm{~mL}$ of anhydrous alcohol } \\
\hline Organic & $285.33 \mathrm{Aa}( \pm 9.77)$ & $250.63 \mathrm{Ba}( \pm 5.35)$ & $202.68 \mathrm{Cb}( \pm 6.70)$ \\
\hline Conventional & $282.8 \mathrm{Aa}( \pm 10.38)$ & $225.25 \mathrm{Bb}( \pm 7.19)$ & $235.37 \mathrm{Ca}( \pm 7.02)$ \\
\hline $\begin{array}{l}\text { Without } \\
\text { fertilization }\end{array}$ & $218.06 \mathrm{Ab}( \pm 4.31)$ & $196.63 \mathrm{Bc}( \pm 6.10)$ & $170.27 \mathrm{Cc}( \pm 7.19)$ \\
\hline
\end{tabular}

Values in the same line, followed by identical capital letters, or in the same column followed by identical lowercase letters indicate that, at the level of significance $(\mathrm{p} \leq 0.05)$, there is no difference among the means.

The means of the values of the higher alcohols (Table 4) varied from $170.27 \mathrm{mg}$ to $285.33 \mathrm{mg}$ per $100 \mathrm{~mL}$ of anhydrous alcohol, in agreement with the national legislation. Barcelos et al. ${ }^{13}$ found values close to the same range ( 176.58 to $235.12 \mathrm{mg}$ per $100 \mathrm{~mL}$ of anhydrous alcohol) in a study where they evaluated cachaças derived from the South of Minas Gerais. Boscolo et al., ${ }^{2}$ also found the mean of $262 \mathrm{mg}$ per $100 \mathrm{~mL}$ of anhydrous alcohol for higher alcohols in cachaças.

Another factor related to the content of these compounds is an adequate distillation process, with a correct correction between the fractions names "head", "heart" and "tail", as they have different concentrations of higher alcohols. ${ }^{13}$

\section{Furfural}

The concentration of furfural, as well as the other volatiles, was determined relating the area of the chromatographic peak in each cachaça converted into concentration by the use of equation (7) (Table 1).

The Tukey's mean of furfural concentration (mg of acetaldehyde per $100 \mathrm{~mL}$ of anhydrous alcohol) in the cachaça by the double interaction was not significant ( $\mathrm{p}$-value $=0.213378$ ), indicating that the variety is not dependent on the management in relation to furfural concentration in the beverages. In the analysis of the means for simple effect, no significant difference was found between the managements without fertilization and conventional $(\mathrm{p}$-value $=0.219382)$. The 
cachaça produced with the organic management was different from the others, presenting the lowest furfural concentration (Table 5).

Table 5. Tukey's means of furfural concentration in the cachaças in the analysis of simple effect for the varieties and for the managements

\begin{tabular}{lc}
\hline \multirow{2}{*}{ Varieties } & Means \\
\cline { 2 - 2 } & $\mathrm{mg}$ per $100 \mathrm{~mL}$ of anhydrous alcohol \\
\hline RB867515 & $1.38^{\mathrm{a}}( \pm 0.23)$ \\
RB855453 & $1.03^{\mathrm{b}}( \pm 0.21)$ \\
RB966928 & $0.74^{\mathrm{c}}( \pm 0.31)$ \\
Managements & Médias \\
Without fertilization & $0.88^{\mathrm{a}}( \pm 0.25)$ \\
Conventional & $1.05^{\mathrm{a}}( \pm 0.17)$ \\
Organic & $0.70^{\mathrm{b}}( \pm 0.22)$ \\
\hline
\end{tabular}

Equal letters indicate that, at the level of significance ( $\mathrm{p} \leq 0.05)$, there is no difference among the means.

The means of furfural concentration varied from $0.74 \mathrm{mg}$ per $100 \mathrm{~mL}$ of anhydrous alcohol to $1.38 \mathrm{mg}$ per $100 \mathrm{~mL}$ of anhydrous alcohol (Table 5) and all are in agreement with the Brazilian legislation, which advocates the value of up to $5.0 \mathrm{mg}$ per $100 \mathrm{~mL}$ of anhydrous alcohol for furfural and hydroxymethylfurfural.

When the furfural concentration among the varieties is evaluated, it is observed that it varied significantly $($ Table 5$)(p$-value $=0.005562)$ indicating that RB966928, regardless of the management, presented almost half the concentration present in the other varieties.

Furfural's presence is harmful to the organism and undesirable in cachaça, since it reduces the quality of the beverage, affecting its aroma and flavor, because of its specific sensory characteristics. The formation of this volatile has several justifications, possibly resulting from the chemical decomposition of carbohydrates, by the degradation of pentoses during the fermentation stage or in distillation by pyrogenization of the organic matter deposited at the bottom of the stills and aging. ${ }^{14,15}$

The mean furfural concentrations in the different cachaças followed the same differences found among the means of the values of total aldehydes (Table 2).

\section{Methanol}

The methanol concentrations ( $\mathrm{mg}$ of methyl alcohol per $100 \mathrm{~mL}$ of anhydrous alcohol) of the cachaça were determined correlating the area of the peak of this compound with the methanol concentration using equation (8) (Table 1).

By the analysis of the Tukey's means, the double interaction was not significant ( $p$-value $=0.58409$ ), indicating that the variety was not dependent on the management in the evaluation of methanol concentration in the beverages. When the variance of the means was evaluated for the analysis of simple effect, no significant difference was found among the varieties ( $p$-value $=0.45494$ ) and for the managements there was significant variation $(p$-value $=0.03768)$ (Table 6).

Methanol has the maximum limit of $20 \mathrm{mg}$ per $100 \mathrm{~mL}$ of anhydrous alcohol. ${ }^{2}$ The means in relation to the level of methanol (Table 6) varied from $2.85 \mathrm{mg}$ to $3.67 \mathrm{mg}$ per $100 \mathrm{~mL}$ of anhydrous alcohol. They are all in accordance with the Brazilian legislation.

The means of the methyl alcohol levels differed significantly between the management without fertilization $(3.67 \mathrm{mg}$ per $100 \mathrm{~mL}$ of anhydrous alcohol) and the organic management (2.85 mg per 100 $\mathrm{mL}$ of anhydrous alcohol), which did not differ significantly from
Table 6. Tukey's means of methanol concentration in the cachaças in the analysis of simple effect for the variety

\begin{tabular}{lc}
\hline \multirow{2}{*}{ Varieties } & Means \\
\cline { 2 - 2 } & mg per $100 \mathrm{~mL}$ of anhydrous alcohol \\
\hline RB 867515 & $3.42^{\mathrm{a}}( \pm 0.80)$ \\
RB 855453 & $3.31^{\mathrm{a}}( \pm 0.83)$ \\
RB 966928 & $3.06^{\mathrm{a}}( \pm 0.78)$ \\
Managements & Means \\
Without fertilization & $3.67^{\mathrm{a}}( \pm 0.60)$ \\
Conventional & $3.30^{\mathrm{ab}}( \pm 0.67)$ \\
Organic & $2.85^{\mathrm{b}}( \pm 0.78)$ \\
\hline
\end{tabular}

Equal letters indicate that, at the level of significance $(\mathrm{p} \leq 0.05)$, there is no difference among the means.

the conventional management $(3.30 \mathrm{mg}$ per $100 \mathrm{~mL}$ of anhydrous alcohol), which also did not differ from the management without fertilization (Table 6). No studies were found correlating the methanol levels with the origin of the cachaça produced from sugarcanes cultivated under different managements.

\section{Coefficient of congeners}

The main components of the distilled beverages are ethanol and water, besides the volatile compounds formed mainly during the stages of fermentation, distillation and storage of the beverage. ${ }^{14}$

The concentrations of the coefficient of congeners of the cachaça were determined correlating the concentration of the volatile acidity, aldehydes, esters, higher alcohols and furfural.

In the analysis of the mean concentrations of the congener coefficient in the cachaças, it was verified in the analysis of variance that the double interaction was significant ( $p$-value $=0.00000000131$ ), indicating that the variety is management dependent in relation to the concentration of the same volatile compound (Table 7).

Table 7. Means of the coefficient of congeners in the cachaças in the unfolding of the double interaction (varieties $\times$ managements)

\begin{tabular}{|c|c|c|c|}
\hline \multirow{3}{*}{ Management } & \multicolumn{3}{|c|}{ Variety } \\
\hline & RB867515 & RB855453 & RB966926 \\
\hline & \multicolumn{3}{|c|}{$\mathrm{mg}$ per $100 \mathrm{~mL}$ of anhydrous alcohol } \\
\hline Organic & $468.62^{\mathrm{Aa}}( \pm 14.06)$ & $415.78^{\mathrm{Ba}}( \pm 16.71)$ & $368.52^{\mathrm{Ca}}( \pm 7.09)$ \\
\hline Conventional & $471.63^{\mathrm{Aa}}( \pm 24.61)$ & $374.35^{\mathrm{Bb}}( \pm 20.39)$ & $312.82^{\mathrm{Cb}}( \pm 7.13)$ \\
\hline $\begin{array}{l}\text { Without } \\
\text { fertilization }\end{array}$ & $378.77^{\mathrm{Ab}}( \pm 9.06)$ & $331.82^{\mathrm{Bc}}( \pm 10.42)$ & $376.41^{\mathrm{Aa}}( \pm 15.90)$ \\
\hline
\end{tabular}

Values in the same line, followed by identical capital letters, or in the same column followed by identical lowercase letters indicate that, at the level of significance $(\mathrm{p} \leq 0.05)$, there is no difference among the means.

The means of the congener levels in all managements varied among all sugarcane varieties, which is noticeable in the capital letters in each line (Table 7). Since this variable is the sum of the volatile acidity, aldehydes, esters, higher alcohols and furfural, these results show that for this variable, the management influences the formation of volatiles during cachaça production. For the cachaça produced from the sugarcane variety RB867515, they differed significantly when the management was without fertilization. The means for the same variable for variety RB855453 differed significantly in all managements (Table 7). Also, the means of the levels of congeners for variety RB966928 differed only in the conventional management. The 
mean of all samples varied from 336.77 to $388.75 \mathrm{mg}$ per $100 \mathrm{~mL}$ of anhydrous alcohol, an approximate value to that found by a study, who evaluated the coefficient of congeners from different cane varieties. ${ }^{16}$

The different sugarcane varieties and fertilization (organic and mineral) contributed and influenced in the chemical profile of the cachaças produced. The means in relation to the level of congeners varied from $312.82 \mathrm{mg}$ to $471.63 \mathrm{mg}$ per $100 \mathrm{~mL}$ of anhydrous alcohol and all are in accordance with the Brazilian legislation, which advocates a range whose value is inferior to $200 \mathrm{mg}$ per $100 \mathrm{~mL}$ of anhydrous alcohol and superior to $650 \mathrm{mg}$ per $100 \mathrm{~mL}$ of anhydrous alcohol.

\section{Volatile acidity}

Among the secondary products, the acetic acid is the most important component of the acid fraction of the cachaças. The volatile acidity in cachaça must not exceed $150 \mathrm{mg}$ of acetic acid per $100 \mathrm{~mL}$ of anhydrous alcohol. ${ }^{2}$

In the analysis of variance of the concentration of acidity in the different cachaças, the double interaction (varieties $\times$ managements) was not significant ( $p$-value $=0.055560$ ), indicating that the variety is not dependent on the management in relation to the concentration of volatile acidity. When the means were analyzed, significant difference was found among the varieties ( $\mathrm{p}$-value $=0.004203$ ) and among the managements $(\mathrm{p}$-value $=0.001163)($ Table 8$)$.

Table 8. Tukey's means of volatile acidity in the cachaças in the analysis of simple effect for the varieties and for the managements

\begin{tabular}{lc}
\hline \multirow{2}{*}{ Varieties } & Means \\
\cline { 2 - 2 } & mg per $100 \mathrm{~mL}$ of anhydrous alcohol \\
\hline RB 867515 & $25.51^{\mathrm{a}}( \pm 11.58)$ \\
RB 966928 & $18.13^{\mathrm{ab}}( \pm 8.71)$ \\
RB 855453 & $14.05^{\mathrm{b}}( \pm 9.97)$ \\
Managements & Means* \\
Organic & $23.15^{\mathrm{a}}( \pm 6.83)$ \\
Conventional & $22.96^{\mathrm{a}}( \pm 13.78)$ \\
Without fertilization & $13.58^{\mathrm{b}}( \pm 6.43)$ \\
\hline
\end{tabular}

Equal letters indicate that, at the level of significance $(p \leq 0.05)$, there is no difference among the means.

The cachaças which presented the highest concentrations of total aldehydes (Table 2) were the same with the highest contents of volatile acidity (Table 8), the same found in a study. ${ }^{17}$ Being the beverages with the highest levels of volatile acidity also presented the highest levels of total esters in the cachaças (Table 3).

All means for the levels of total acidity are inside the legislation (150 mg of acetic acid per $100 \mathrm{~mL}$ of anhydrous alcohol) and varied from 14.04 to $25.51 \mathrm{mg}$ of acetic acid per $100 \mathrm{~mL}$ of anhydrous alcohol (Table 8). The varieties differed from each other, with variety RB855453 being different in terms of mean from variety RB867515, but variety RB867515 did not differ in mean from variety RB966928 and this from variety RB855453 for the same variable. Variety RB867515 presented the highest concentration for the variable volatile acidity.

Evaluating the means of the volatile acidity levels (Table 8) of the cachaças which received organic or conventional fertilization, both presented the highest content of volatile acidity and did not differ from each other. Only the beverage produced with the sugarcane from the management without fertilization differed from the others, presenting the lowest acidity value. This result can be attributed to the concentration of the acidity of soil fertility because of the fertilizations (organic or mineral). According to De Almeida Junior et al. ${ }^{18}$ the contents of fixed soil acidity are directly related to its fertility, and the more fertile the soil, the higher is the content of acids that can be absorbed by the plant.

\section{n-Butanol}

The concentrations of $n$-butanol ( $m g$ of $n$-butanol alcohol per 100 $\mathrm{mL}$ of anhydrous alcohol) of the cachaça were determined correlating the peak area of this component with the n-butanol concentration using equation (9) (Table 1).

The results evaluated and subjected to the analysis of variance at the level of $5 \%$ of significance $(\mathrm{p}<0.05)$ and Tukey's multiple comparisons test of the n-butanol concentration indicated that the double interaction was not significant ( $\mathrm{p}$-value $=0.054372$ ). Thus, the variety was not dependent on the management in relation to the concentration of n-butanol. The Tukey's means were evaluated for the analysis of simple effect, no significant difference was found among the variables ( $\mathrm{p}$-value $=0.47385$ ) and among the managements $(\mathrm{p}$-value $=0.48792)($ Table 9$)$.

Table 9. Means of the n-butanol concentration in the cachaças in the analysis of simple effect for the varieties and for the managements

\begin{tabular}{lc}
\hline \multirow{2}{*}{ Varieties } & Means \\
\cline { 2 - 2 } & mg per $100 \mathrm{~mL}$ of anhydrous alcohol \\
\hline RB 855453 & $1.20^{\mathrm{a}}( \pm 0.28)$ \\
RB 966928 & $1.17^{\mathrm{a}}( \pm 0.71)$ \\
RB 867515 & $0.96^{\mathrm{a}}( \pm 0.37)$ \\
Managements & Means* \\
Without fertilization & $1.19^{\mathrm{a}}( \pm 0.13)$ \\
Conventional & $1.08^{\mathrm{a}}( \pm 0.08)$ \\
Organic & $1.06^{\mathrm{a}}( \pm 0.23)$ \\
\hline
\end{tabular}

Equal letters indicate that, at the level of significance $(\mathrm{p} \leq 0.05)$, there is no difference among the means.

The means in relation to the n-butanol level (Table 9) varied from $0.96 \mathrm{mg}$ to $1.20 \mathrm{mg}$ per $100 \mathrm{~mL}$ of anhydrous alcohol. All samples are in agreement with the Brazilian legislation. The means of the n-butanol levels were not significantly different among the managements and varied from $1.06 \mathrm{mg}$ per $100 \mathrm{~mL}$ of anhydrous alcohol for the organic management to $1.19 \mathrm{mg}$ per $100 \mathrm{~mL}$ of anhydrous alcohol for the management without fertilization. Furthermore, no studies were found correlating the n-butanol levels with the origin of the cachaça produced from sugarcanes cultivated under different managements. Schmidt et al., ${ }^{19}$ analyzed cachaças derived from the State of Rio Grande do Sul and found values above the allowed by the Brazilian legislation of the contaminant n-butanol. This result is contrary to that found in the present work.

\section{CONCLUSIONS}

In this study no volatile compounds were found with values above national legislation.

The concentration of total esters, higher alcohols and coefficient of congeners in cachaças were dependent on varieties and cultivation systems. However, the concentration of volatile acidity, total aldehydes, alcohol, methanol, n-butanol and furfural in cachaças were independent of variety and cultivation systems. The variety RB 867515 showed the highest concentrations among the volatile 
compounds. Therefore, the most suitable for the production of cachaça.

For cultivation systems, the organic method showed higher concentrations among volatile compounds, making it the most recommended cultivation system, followed by the conventional cultivation system. Thus, the quality, origin and lineage of the sugarcane variety for the production of cachaça influence the chemical concentrations of the volatile compounds of the beverage, modifying the chemical profile.

\section{REFERENCES}

1. Almeida, M. E. W. de; Barreto, H. H. C.; Rev. Inst. Adolfo Lutz. 1971, $31,117$.

2. Brasil, Instrução Normativa $\mathrm{n}^{\circ} 13$, de 29 de junho de 2005. Diário Oficial da União, Brasília, DF, 30/06/2005. Seção 1, p. 30.

3. Boscolo, M.; Bezerra, C. W.; Cardoso, D. R.; Lima Neto, B. S.; Franco, D. W. J. Braz. Chem. Soc. 2000, 11, 86.

4. Alcarde, A. R.; de Souza, P. A.; Belluco, A. D. S.; Cienc. Tecnol. Aliment. 2010, 30, 226.

5. Cardoso, M. D. G.; Zacaroni, L. M.; Santiago, W. D.; Rodrigues, L. M. A.; Pereira, J. G. M.; Fátima, F. C. D.; Silva, R. C.; Agrotechnica: Revista Técnico-Científica Agrícola. 2012, 3, 98.

6. Brasil, Lei $\mathrm{n}^{\circ} 10.831$, de 23 de Dezembro de 2003. Diário Oficial da União, Brasília, DF, 24 dez. 2003, Seção, p. 15.

7. Brasil, Instrução Normativa $\mathrm{n}^{\circ} 24$, de 20 de setembro de 2005. Diário Oficial da União, Brasília, DF, 20 set. 2005. Seção 1, p. 11.
8. $\mathrm{R}$ Development Core Team; $R$ : A language and environment for statistical computing; R Foundation for Statistical Computing, Austria.

9. Daros, E.; Oliveira, R. A.; Barbosa, G. V. S.; 45 years of RB varieties of sugarcane: 25 years of Ridesa, $1^{\mathrm{a}}$ ed., Graciosa: Curitiba, 2015.

10. Margarido, L. A. C.; Verruma-Bernardi, M. R.; Borges, M. T. M. R.; Lopes, C. H.; Higiene Alimentar 2008, 22, 161.

11. Lima, A. D. J. B.; Cardoso, M. D. G.; Guerreiro, M. C.; Pimentel, F. A.; Quim. Nova 2006, 2, 247.

12. Alcarde, A. R.; Souza, P. A. D.; Belluco, A. E. D. S.; Cienc. Tecnol. Aliment. 2010, 30, 226.

13. Barcelos, L. V. F.; Cardoso, M. D. G.; Vilela, F. J.; Anjos, J. P. D.; Quim. Nova 2007, 30, 1009.

14. Yokoya, F.; Fabricação de aguardente de cana. Fundação Tropical de Pesquisas e Tecnologia "André Tosello": Campinas, 1995.

15. Cardoso, M. das G.; Produção de Cachaça de Cana, $2^{\text {th }}$ ed., UFLA: Lavras, 2006

16. Moreno, M. V. G.; Barroso, C. G.; J. Agric. Food Chem. 2002, 50, 7556.

17. Silva, J. H. N.; Margarido, L. A. C.; Borges, M. T. M. R.; VerrumaBernardi, M. R.; Revista Científica do Centro Universitário de Araras "Dr. Edmundo Ulson" - UNAR. 2004, 9, 1.

18. De Almeida Júnior, A. B. D.; Do Nascimento, C. W.; Sobral, M. F.; Da Silva, F. B.; Gomes, W. A.; Rev. Bras. Eng. Agríc. Ambient. 2011, 15, 1004.

19. Schmidt, L.; Marmitt, S.; Oliveira, E. C.; De Souza, C. F. V.; Aliment. Nutr. 2009, 20, 539. 